\title{
El marxismo en la reconceptualización: ¿De qué marxismo se trata?
}

\author{
Marxism in reconceptualization: What Marxism is it about?
}

Sergio Quintero Londoñoa

Resumen: El artículo analiza algunas características del marxismo en la reconceptualización. Se reflexiona sobre las condiciones de las décadas 1960-1970, donde producto de las contradicciones socio-históricas, se genera una pluralidad en los fundamentos teórico-metodológicos. Se demuestra cómo el marxismo incursiona en el Trabajo Social a partir de diversas fragmentaciones del corpus teórico de Marx, desconociendo la crítica de la economía política, y por tanto disolviendo la perspectiva de totalidad.

Palabras claves: Capital. Reconceptualización. Marxismo. Valor.

\begin{abstract}
In this article we analyze some characteristics of marxism in the reconceptualization. It reflects on the conditions of the decades 1960-1970, where product of the socio-historical contradictions, generates a plurality in the theoretical-methodological foundations. It shows how Marxism ventures into Social Work from various fragmentations of Marx's theoretical corpus, ignoring the critique of political economy, and therefore dissolving the perspective of totality.
\end{abstract}

Keywords: Capital. Reconceptualization. Marxism. Value.

\section{Introducción}

\begin{abstract}
A 1 considerar que el Trabajo Social emerge y se profesionaliza en 1 el periodo capitalista en que los monopolios se han tornado he- gemónicos, debemos ser conscientes que la "historia profesional" es relativamente nueva. Sin embargo, debido al momento socio-histórico en que constituye sus trazos fundamentales como profesión inscrita en la
\end{abstract}

aCandidato a Doctor en Servicio Social por la Universidad del Estado de Rio de Janeiro (UERJ), Rio de Janeiro-RJ, Brasil. 
división socio-técnica del trabajo, nutrida por las contradicciones teóricas y políticas de la lucha de clases, también debemos reconocer que (pese a su corta historia), el Trabajo Social ha presentado varios periodos en los cuales se encuentra gran diversidad de tensiones y contradicciones.

Sin entrar en un análisis extensivo sobre "la historia del Trabajo Social", es conveniente mencionar que su constitución (génesis y desarrollo) se da como resultado de las contradicciones de la sociedad capitalista en la que las clases dominantes se encuentran obligadas a dar un tratamiento diferencial a la cuestión social, más allá de las medidas policiacas y represivas que caracterizaron el siglo XIX. (Iamamoto e Carvalho, 1984).

La estructuración de la profesión avanza desde sus protoformas hasta alcanzar ciertos fundamentos teórico-metodológicos, con los cuales incorpora elementos de las ciencias positivas (caracterizada por el pragmatismo y el instrumentalismo). Posterior a la segunda mitad del siglo XX, en el Movimiento de la Reconceptualización se presenta el ingreso del marxismo como arsenal heurístico con potencialidades para la explicación de las contradicciones socio-históricas, y para dar respuesta a las manifestaciones de la cuestión socia. En este contexto, la diversidad y enfrentamiento entre el positivismo y el marxismo se presenta como consecuencia de las contradicciones del modo de producción que determinan la profesión, y no como un proceso correspondiente a las fuerzas endógenas del Trabajo Social. (Netto, 2000; 2012).

\section{Incorporación del marxismo al Trabajo Social}

Los años 60 y 70 del siglo XX irrumpen con una crisis estructural que impacta todas las esferas del capitalismo. Las consecuencias de tal crisis se hacen expresivas al interior de la institucionalidad educativa (especialmente las universidades), en la que se reflejan las contradicciones entre diferentes propuestas teórico-metodológicas, que traen consigo ideas de proyectos societarios diametralmente opuestos. 
La dinámica de crisis y antagonismos presenta su mayor expresión en el Trabajo Social a través del Movimiento de la Reconceptualización, donde se genera una diversidad de pensamiento que pluraliza los fundamentos de la profesión, e incorpora debates de carácter político e ideológico de las clases sociales en pugna. En otras palabras, a través de la Reconceptualización, la profesión entra de forma explícita y consciente en la contradicción política del orden capitalista, enfrentando la supuesta neutralidad valorativa, y poniendo en tensión la estructura clásica con la que el pensamiento conservador mantenía una matriz de pensamiento ideológico reproductor de las relaciones sociales de dominación.

Uno de los principales avances de la Reconceptualización es la constitución de pluralidad teórico-metodológica; al interior de este avance se evidencia la máxima expresión con el ingreso del marxismo como interlocutor válido, plenamente reconocido por las demás tendencias teórico-metodológicas. Sin embargo, el ingreso del marxismo al Trabajo Social (al igual que en otras profesiones, en las "disciplinas de las Ciencias Sociales" y en organizaciones político-partidarias) no se da sin contradicciones y límites.

Basados en la premisa de que son las contradicciones del capital las que determinan la profesión (sin dejar de reconocer la autonomía relativa de ésta), consideramos que las características particulares a través de las cuales entra el marxismo al Trabajo Social encuentran su explicación en la totalidad del modo de producción capitalista. El análisis del Trabajo Social en la historia (diferente a "la historia del Trabajo Social"), permite entender que la incursión del marxismo al debate profesional obedece al contexto socio-histórico (particularmente del contexto convulsionado de América Latina en las décadas 1960 y 1970) y heurísticamente está vinculado al desarrollo teórico-político del movimiento socialista-comunista (y sus divergencias) a nivel mundial ${ }^{1}$.

1. Una exposición clara sobre el marxismo en Trabajo Social como un reflejo del debate de los partidos políticos y el movimiento comunista a nivel mundial, es presentada por Consuelo Quiroga, 2000. 
Durante todo el siglo XX, el análisis histórico-sistemático de Karl Marx se configuró en piedra angular para la comprensión de las relaciones del modo de producción capitalista, sin embargo, su apropiación por diferentes sectores académicos y políticos no representó per se una apropiación adecuada, ni mucho menos una profundización de sus fundamentos. Por el contrario, lo que caracterizó al marxismo en su gran mayoría fue una incorporación parcializada y precarizada de la teoría social de $\mathrm{Marx}^{2}$.

En este sentido, si la apropiación de la teoría social de Marx se da con dificultades al interior del movimiento socialista-comunista, es una consecuencia objetiva el hecho de que tales dificultades también se presenten y hasta se profundicen al interior del Trabajo Social Reconceptualizado, en tanto que, fundamentalmente, es a través de movimientos y organizaciones políticas que se incorpora el marxismo a la profesión.

Ahora bien; ¿cuáles son los fundamentos estructurales desarrollados por Marx sobre los cuales se presentan profundas diferencias en las interpretaciones "marxistas"?

De acuerdo a la célebre expresión de Lenin, son tres fuentes y tres partes integrantes del marxismo las que se deben reconocer como arsenal heurístico. En las tres fuentes, Karl Marx se encargó de incorporar y superar (o superar-conservando) lo mejor del socialismo francés, la economía clásica inglesa y la filosofía alemana. Cada uno de estos procesos se convirtió en pilar indispensable e indisoluble de la teoría marxiana, consolidando una teoría crítica con mayor potencia explicativa y transformadora. Sólo la comprensión relacional y dialéctica que de allí se desdobla (la perspectiva revolucionaria, la crítica de la economía política y el método dialéctico-materialista) pueden dar cuenta de las contradicciones y leyes tendenciales del modo de producción capitalista, como condición ineludible para su transformación.

Teniendo en cuenta lo anterior, es necesario revisar, aunque sea de forma introductoria, en qué consiste la tergiversación y apropiación limitada

2. Aquí no se aborda el debate de cuáles son las tendencias herederas de Marx que mejor incorporaron su propuesta teórico-metodológica, sin embargo vale la pena una referencia a Lukács cuando llama la atención sobre la "paralización" y "petrificación" del marxismo durante el periodo stalinista y la Tercera Internacional. 
de pensamiento de Marx por parte de movimientos y partidos políticos, las "Ciencias Sociales" y el Trabajo Social.

Se podrían enumerar varios limites-tergiversaciones del marxismo, sin embargo, para efectos del presente trabajo, tan sólo se retoman algunos, que a nuestro modo de ver, configuran los mayores límites para el desarrollo de la crítica marxiana.

- Confundir la crítica con el ente criticado: no es extraño que cualquiera de las críticas desarrolladas por Marx sea incorporada en la forma que él intenta superar; esto sucede de forma reiterada con la teoría de los economistas clásicos (Smith, Ricardo y otros) que planteaban la valorización del valor como un proceso originado en la circulación. De igual forma sucede con la filosofía idealista (principalmente Kant y Hegel) en la que la consciencia determina el ser, y no el ser a la consciencia. Y con el socialismo utópico (Saint Simon, Fourier, Owen y otros) para quienes el politicismo o los criterios morales, no pocas veces caracterizados por el voluntarismo, se expresan como alternativas (subjetivas) de superación del orden capitalista.

- Dividir los elementos integrantes de un proceso indivisible: el pretender colocar la teoría de Marx como una más de las "Ciencias Sociales" conllevó a la disolución de la perspectiva de totalidad; consecuencia de ello fue la edificación de fronteras claramente definidas al interior de las ciencias, que buscan delimitar objetos, métodos y teorías propias-específicas. En el campo profesional, la búsqueda de teorías y métodos propios estimuló la creación de una supuesta especificidad, que reproduce el carácter fragmentario de las "Ciencias Sociales". La división de la historia, la política y la economía hicieron de la totalidad concreta (modo de producción capitalista) una suma de "factores" o "esferas" que en la teoría no guardan relación dialéctica entre sí.

- Incorporar de manera unilateral la interpretación política de Marx: Como consecuencia del auge de las luchas políticas durante el periodo 1960-1970, se sobreponen interpretaciones politicistas que subestiman o ignoran el carácter determinante de las relaciones de 
producción. En su gran mayoría, los postulados del politicismo se fundamentan en una crítica moral de la explotación, haciendo propuestas que se limitan a la distribución de la riqueza social, dejando intacta la forma de producción.

- Establecer falsas jerarquías al interior de la totalidad: con el objetivo de superar el subjetivismo (o el politicismo) que caracteriza algunas corrientes "marxistas", el economicismo toma tal fuerza que se presenta como causa predeterminada de las consecuencias políticas, dando lugar al mecanicismo divulgado por los manuales del "socialismo real". Se sobrevalora la expresión de que "la estructura determina la superestructura" configurando un determinismo que poco o nada tiene que ver con la dialéctica al interior de los elementos que constituyen la totalidad, o con el momento ontológicamente predominante.

Estos y otros límites incorporados en el marxismo se convirtieron en factores decisivos para la neutralización o eliminación del potencial revolucionario de la teoría marxiana. En nombre del marxismo se intentaron legitimar análisis parcializados y decisiones políticas que generaron fuertes cuestionamientos (teóricos y políticos) a nivel mundial. El epistemologismo, queriendo hacer de la teoría social de Marx un simple desarrollo académico; al igual que el politicismo, cayendo en voluntarismos pseudo-revolucionarios, instrumentalizaron la teoría marxiana, equiparándola con cualquier otro desarrollo de las "Ciencias Sociales".

Las principales obras de Marx que fueron apropiadas en el debate teórico corresponden a aquellas dirigidas al análisis de coyunturas y situaciones políticas específicas, o documentos político-partidarios; entre esas obras se corona como obra prima el Manifiesto del Partido Comunista, y otras subsidiarias como El dieciocho brumario de Luis Bonaparte, La ideología alemana, Crítica al Programa de Gotha, entre otras de menor difusión ${ }^{3}$.

3. En este artículo no se niega el valor que estas obras tienen en la producción teórica de Karl Marx; el principal objetivo corresponde a entender que un análisis parcializado, sea político, económico o histórico, es insuficiente para entender las leyes tendenciales del modo de producción capitalista. 
Un análisis filológico de los textos mencionados podría evidenciar claramente que la exposición de Marx no pretende limitar su comprensión a las contradicciones políticas de situaciones coyunturales determinadas, sino que desarrolla un análisis histórico-sistemático, a través del cual presenta las contradicciones políticas como expresiones de otras contradicciones más profundas, es decir, como formas a través de las cuales se manifiesta la totalidad concreta. Sin reducir el valor que en sí guardan las relaciones políticas, Marx encuentra su raíz, no en las contradicciones políticas stricto sensu, sino en la base estructural de la producción, de donde se desdoblan todos los desarrollos y contradicciones del Ser Social ${ }^{4}$. Es justo aquí donde se identifica el mayor límite del marxismo en el Trabajo Social, al abordar de forma limitada, o simplemente al no abordar El Capital (y en general toda la crítica de la economía política), obra que constituiría la piedra angular de Marx para la comprensión de la sociedad moderna.

En síntesis, la mayor dificultad que estamos advirtiendo al interior del marxismo y de la Reconceptualización es la fragmentación de las tres partes integrantes, con especial desconocimiento de la crítica de la economía politica ${ }^{5}$.

\section{Contribuciones para superar los límites}

Para Marx el objetivo de la ciencia es captar el movimiento contradictorio de la realidad social, que se constituye en leyes tendenciales propias

4. En apariencia, con esta expresión estaríamos cayendo en el límite criticado anteriormente al establecer falsas jerarquías, sin embargo, no es eso de lo que se trata en esta situación. En Marx es claro que la relación entre la producción, circulación, distribución y consumo, analizadas a lo largo de la crítica de la economía política, es una relación indisoluble que comprende en su debida proporción el peso de cada momento; así entonces, de forma ontológica, Marx demuestra la primacía (como momento predominante) de la producción sobre los demás momentos de la rotación del capital. Al entender el Capital no como cosa, sino como la relación social que rige el mundo contemporáneo, es posible captar la primacía de las relaciones de producción, sobre los demás escenarios de socialización.

5. De acuerdo con nuestra interpretación, es a partir de esos límites que se desdoblan equívocos de gran envergadura en la profesión, tal y como el mesianismo de la Reconceptualización; el cual presenta reediciones contemporáneas en algunos sectores del cuerpo profesional. Sobre el mesianismo y fatalismo en el Trabajo Social, ver Iamamoto 2001, y el texto supracitado de Consuelo Quiroga. 
de un tipo de sociedad determinado; en este caso, el modo de producción capitalista $^{6}$. Superar la interpretación o descripción de los elementos superficiales, y llegar al reconocimiento de la lógica a través de la cual se desarrolla el capital (su dinámica inmanente), constituye el camino que debe ser recorrido en el ejercicio investigativo.

Pese a reconocer la importancia (y límites) de las descripciones, cuantificaciones y clasificaciones (propias del pensamiento positivista), al igual que las interpretaciones, causalidades, sentidos y significados (sobre los cuales se desarrolla el comprensivismo), Marx se preocupa por descubrir las leyes tendenciales de la sociedad capitalista, tendencias que no se manifiestan de forma plena y explícita en la superficialidad de las relaciones o en la vida cotidiana.

Después de acumular gran parte del debate filosófico y político desarrollado hasta entonces (segunda mitad del siglo XIX), Marx alcanza su mayor nivel de comprensión sobre el modo de producción capitalista al plantear la crítica de la economía política, expuesta principalmente en Los Grundrisse escritos entre 1857-1858, en la Contribución a la Crítica de la Economía Política publicado en 1859, y de forma más acabada en El Capital, el cual, lleva por subtítulo Crítica de la economía política ${ }^{7}$.

El objetivo de su crítica queda claro en el prólogo a la primera edición de El Capital:

Lo que de por sí nos interesa, aquí, no es precisamente el grado más o menos alto de desarrollo de las contradicciones sociales que brotan de las leyes

6. Marx capta el movimiento de la realidad como ley tendencial que se caracteriza por la tensión permanente de contratendencias. Por su parte, el positivismo pretenden alcanzar o evidenciar leyes absolutas, y muchas veces ahistóricas.

7. Aunque la estructura más organizada de la crítica de la economía política adquiere una forma expositiva a finales de los años 50 y durante los años 60, no hay que olvidar que desde 1844 Marx inaugura sus estudios "económicos" con los Manuscritos económico-filosóficos.

No sobra recordar que Marx sólo alcanza a publicar el libro I de El Capital (el proceso de producción) en 1867. Los libros II (el proceso de circulación) y III (el proceso de producción capitalista en su conjunto) son publicados por Engels en 1885 y 1894 respectivamente, y el libro IV (teoría de la plusvalía) es publicado por Kautsky en la primera década del siglo XX.

Un análisis detallado de la forma en que se va consolidando la crítica marxiana a la economía política se encuentra en Rosdolsky, 1989. 
naturales de la producción capitalista. Nos interesan más bien estas leyes de por sí, estas tendencias, que actúan y se imponen con férrea necesidad. (Marx, 1976, XIV)

Queda claro que las formas en las que se presentan las leyes tendenciales no son el objeto central de análisis para la comprensión de la sociedad capitalista, aunque sea a través de éstas que se consigue develar la esencia del mismo. El objeto central de análisis es la lógica a través de la cual se desarrolla el Ser Social en el modo de producción capitalista; la dinámica inmanente que encuentra su núcleo fundamental en el valor.

Desde el primer lustro de los años 40 y todo el tiempo corrido hasta 1883 (año de su muerte), Marx confronta los planteamientos "científicos" preestablecidos por la ciencia burguesa. Consigue develar que a partir del 1830-1848, producto de la lucha de clases y especialmente con la pérdida del carácter revolucionario en la burguesía, la ciencia (burguesa) pasa a tener un carácter conservador en tanto que se plantea como principal objetivo la defensa del orden social establecido, y no la búsqueda de las leyes fundamentales de la realidad. La filosofía burguesa entra en un proceso de decadencia, recayendo no sólo en el idealismo, sino también en la reproducción ideológica del orden burgués. Por su parte, la economía política clásica es remplazada por la economía vulgar, y los economistas burgueses, al decir de Marx, se convierten en espadachines a sueldo (mercenarios) en defensa del capital.

Con base en lo anterior es necesario preguntar cómo comprende Marx que debe ser el ejercicio investigativo. La respuesta a este interrogante no es una formula instrumental, sino una premisa orientadora de carácter fundamental: la principal herramienta con la que se cuenta en el estudio de las relaciones sociales es la abstracción; es a través de ésta que se identifican la singularidad del objeto analizado, y sus mediaciones con la totalidad.

Uno de los principales logros de Marx al indagar la realidad a partir de la dialéctica materialista es descubrir que cada periodo histórico tiene características propias que lo diferencian de periodos anteriores. Es por ello que la producción teórico-política de Marx se encarga de mostrar las 
particularidades del modo de producción capitalista, que no se reduce a la lucha entre "burgueses y proletarios", sino que da cuenta de la compleja producción-relación mercantil y sus expresiones (sociales, políticas, económicas y culturales).

La perspectiva de historicidad niega los análisis hipostasiados de la ciencia y la filosofía burguesa, que confunden el presente con el pasado y éste con el futuro, negando alternativas sociales diversas a la implantada por el capital. El debate directo con la economía clásica, especialmente con Smith y Ricardo, le permite demostrar a Marx que uno de los principales errores de la ciencia burguesa es trasladar categorías propias de un periodo histórico hacia otro, tergiversando o negando por completo las nuevas características que determinan la sociedad moderna.

Tal vez el principal aporte de la crítica de la economía política es el descubrimiento del valor como mediación inherente de las relaciones sociales en el capitalismo. Sin embargo, esta categoría brilla por su ausencia en los estudios "marxistas", y especialmente en los debates de la Reconceptualización.

En su obra madura, Marx despliega el análisis para demostrar cómo el valor es una característica propia y exclusiva del capitalismo a través de la cual las relaciones sociales se presentan de forma fetichizada. Sólo en la sociedad capitalista el valor adquiere su pleno desarrollo, hasta llegar a determinar la forma en que los individuos se relacionan entre sí.

Explicando la forma en que surge y se desarrolla el valor, quedan claras las características particulares que adquieren ciertas categorías en las relaciones capitalistas. Algunas categorías que van a encontrar su máximo nivel de desarrollo en el capitalismo ya se encontraban presentes en modos de producción pre-capitalistas; tal es el caso de la propiedad, dominación, explotación, la propiedad privada, división del trabajo, alienación, dinero, entre otras. Sin embargo, en el momento que el valor entra a configurar la mediación fundamental a través de la cual se establecen las relaciones sociales, tales categorías adquieren nuevas características.

Con base en la obra madura de Marx es posible plantear que el valor es la categoría central que determina (aunque no de forma mecánica y 
unidireccional) otras categorías de gran relevancia en la sociedad capitalista; esta expresión recupera el carácter predominante de la ontología marxiana, profundizando las raíces del análisis, al pasar de observaciones superficiales de la circulación, hasta llegar a la producción. Ahora bien, el análisis más profundo de la producción no se agota allí, sino que encuentra su relación con la circulación, vistas en un proceso complementario e indisoluble ${ }^{8}$.

El valor es el ente que rige la producción, circulación, distribución y consumo de mercancías, constituyendo una división social del trabajo en la que los productores individuales se relacionan entre sí a través de sus productos, de su trabajo objetivado. En otras palabras, en el marco de la sociedad capitalista la relación mercantil (de valor) es la que (predominantemente) posibilita las relaciones sociales.

Las relaciones sociales en contextos pre-capitalistas se caracterizan por la relación directa entre los individuos, sin necesidad de ocultar su mutua dependencia; es decir, debido a que existe dependencia personal, las relaciones sociales se dan de forma clara; los hombres se relacionan y dependen mutualmente los unos de los otros de forma directa. Contrario a eso, en la sociedad capitalista las relaciones sociales recurren a una mediación a través de la cual los individuos tienen contacto entre sí; tal mediación es el valor, que necesariamente adquiere materialidad en las mercancías.

Este tipo de relaciones fetichizadas, al decir de Marx, presenta las relaciones sociales como relaciones entre cosas, y las relaciones entre cosas como relaciones sociales; además, tal inversión se presenta como natural ${ }^{9}$.

A primera vista podríamos responder con Marx que "lo que aqui reviste, a los ojos de los hombres, la forma fantasmagórica de una relación entre

8. De esta manera, para comprender en la obra de Marx el modo de producción y sus leyes tendenciales no basta con el abordaje del primer tomo de El Capital (proceso de producción) o del segundo (el proceso de circulación), sino que debe ser vista la obra en su conjunto. Además se debe tener claro que la crítica de la economía política no es una teoría económica, sino una obra que analiza las relaciones sociales sobre las cuales se desarrolla el capitalismo.

9. El fetiche no es un proceso de abstracción sino una forma de ser de lo concreto en la sociedad capitalista; en ese sentido, el fetiche no puede ser eliminado por la investigación objetiva (que revela la esencia), sino por la transformación del objeto. 
objetos materiales no es más que una relación social concreta establecida entre los mismos hombres" (Marx, 1976, p. 38). Por demás, se debe mencionar que ésta ha sido la respuesta parcial más utilizada por diversos sectores al interior del marxismo; sin embargo esta respuesta, no deja de ser eso, una respuesta parcial. Veamos por qué.

En el proceso de producción capitalista, entendido éste como producción y reproducción, el capital constante cada vez adquiere mayor magnitud frente al capital variable. Con el desarrollo de la gran industria, en el proceso de producción ya no es el trabajador el que controla a las máquinas, sino éstas a aquel; el trabajo muerto controla al trabajo vivo. Además, en la circulación, como fue mencionado anteriormente, son las mercancías las que permiten la socialización entre los productores individuales; las personas se relacionan a través de las cosas (mercancías). De esta manera, el hecho de que las relaciones sociales se presenten como relaciones entre cosas, y por ellas dominadas, no es simplemente cuestión de apariencia, sino que es la forma en que se desarrolla el capital; las relaciones sociales aparecen como lo que son.

Si se pretende responder con los planteamientos radicales de Marx a la forma fetichizada en que se presentan las relaciones sociales en el capitalismo, no será suficiente con develar el secreto a través del cual queda claro que los son hombres (al transformar la naturaleza) quienes crean la riqueza material y constituyen toda la realidad, tanto política como económica. Será necesario ir mucho más allá, al demostrar que esta inversión es inherente al capital y sólo podrá ser superada con la construcción de otro modo de producción. Si como dice Marx, el fetiche es propio del capitalismo, y de éste no se puede eliminar, la superación del fetiche necesariamente es la superación del capital.

En la transformación ininterrumpida del valor es que se desarrolla el capital (no como cosa sino como relación) tanto en el proceso de producción como en la distribución; de ello dan cuenta las metamorfosis del valor analizadas por Marx en el Libro II (capital-dinero, capital-productivo y capital-mercantil) y en el Libro III (donde expone la forma y los sectores en que tal valor se distribuye como renta, salario y lucro) de El Capital. 
Teniendo en cuenta que la lógica o esencia de esta sociedad se presenta de diferentes formas, vale la pena llamar la atención sobre la centralidad que al interior de ciertas tendencias "marxistas" se ha otorgado sobre algunas de estas manifestaciones, disminuyendo importancia, o incluso en algunos casos, dejando de lado el análisis del valor.

En algunos análisis que priorizan el debate político, se presenta la explotación como la categoría central a partir de la cual se consolida y reproduce el sistema capitalista; al parecer, es con la explotación, (asumida como apropiación del trabajo ajeno) desde donde se desdobla toda forma de relación social capitalista. La respuesta lógica (y limitada) del marxismo vulgar corresponde al fin de la explotación y a la distribución más equitativa de la riqueza social, enfocando sus argumentos al proceso de circulación, olvidando el momento predominante de la producción. El capitalismo se resume a un problema de distribución de riqueza, desconsiderando su abordaje como una forma alienada de producción y reproducción social. Este se convierte en el principal argumento de las organizaciones políticas que actúan en América Latina durante los años 60 y 70, con los cuales corresponde el debate académico-político de la Reconceptualización.

A nuestro modo de ver, si se tiene en cuenta lo dicho sobre el valor, estas premisas, aunque hegemónicas, son ciertas, pero parciales; o dicho en otros términos, son parte de la explicación de la lógica del capital, aunque no su explicación plena. Si se considera el valor como eje central del modo de producción capitalista, se debe entender que el fin último de la explotación, que es desarrollada a través de la propiedad privada de los medios de producción, es justamente la creación de valor y su desarrollo creciente, el cual no puede ser entendido como relaciones económicas, sino como relaciones sociales propias del capital. El valor como categoría central se encuentra tanto en la producción como en la circulación de mercancías, y a su vez son éstas las que se encargan de garantizar la reproducción social y las relaciones sociales.

Si de lo que se trata es de enfocar la centralidad del capitalismo, el núcleo de análisis debe partir de la comprensión del valor y avanzar hacia 
la explotación (esta es la forma en que Marx realiza su exposición). No importa que el valor tenga su origen en la producción, puesto que su campo de influencia va mucho más allá, llegando a la determinación dialéctica de la política y la cultura. En síntesis, el análisis del valor no se reduce al campo meramente económico, sino que comprende la lógica del capital como una lógica general que abarca la totalidad de las relaciones sociales.

Ahora bien, el hecho que la explotación, la propiedad privada de los medios de producción, la apropiación privada del trabajo social, y otras tantas categorías del capital sean consecuencias directas le la lógica del valor, no quiere decir que estas tengan que pasar a un segundo plano, perdiendo el peso que en sí tienen al interior del capital. Contrario a ello, la creación de valor no será posible si tales condiciones no están dadas en la forma que asumen bajo el régimen capitalista. De esa manera, la centralidad del valor no será tal, si no se entiende su relación congénita con otras tantas categorías que posibilitan la valorización del valor.

Al abordar el valor de forma autónoma y autosuficiente se extrapolan sus características, tergiversando la forma real en la que éste se presenta. Hay quienes creyendo entender la importancia del valor, le otorgan cualidades extralimitadas, hasta el punto de asumir literalmente la lógica automática en la que éste se desarrolla. Si bien, la ley del valor es la que determina la sociedad capitalista, y no depende de la voluntad de los hombres que aparecen como personificaciones de categorías económicas (sean ellos capitalista o asalariados), no es posible plantear la independencia plena del valor con respecto a los sujetos y por tanto a la lucha de clases. El valor no es un sujeto autónomo que avanza indefinidamente y de forma natural al margen de las contradicciones de los sujetos; plantear esto es tan equivocado como el hecho de creer que el fetiche se supera cuando se develan las relaciones sociales en el intercambio de mercancías.

En el tomo II de El Capital, Marx insiste en la lógica del valor como una cuestión autónoma del desarrollo capitalista, sin embargo ello no significa una autonomía stricto sensu, subvalorando otras categorías de gran relevancia, como por ejemplo la explotación. Para Marx, tal y como fue planteado 
anteriormente, el valor no se desarrolla aisladamente, sino que requiere un conjunto de condiciones propias del modo de producción capitalista.

Veamos la complementariedad que Marx coloca en el análisis entre el valor y la explotación:

El capital, como valor que se valoriza, no encierra solamente relaciones de clase, un determinado carácter social, basado en la existencia del trabajo como trabajo asalariado. Es un movimiento, un proceso cíclico a través de diferentes fases, que, a su vez, se haya formado por tres diferentes etapas. [capital-dinero, capital-productivo, capital-mercancía]. (...) Quienes consideran una pura abstracción la sustantivación del valor olvidan que el movimiento del capital industrial es precisamente esta abstracción hecha realidad. (Marx, 1975, p. 94)

A primera vista, esa expresión de Marx confirma la existencia autónoma del valor frente las dinámicas y decisiones de los seres humanos agrupados en clases sociales, sobredimensionando la ley del valor y cayendo en abstracciones idealistas o en el economicismo. Sin embargo, inmediatamente después de explicar el movimiento constante a través de las metamorfosis del capital y su ciclo, el mismo Marx llama la atención sobre la relación de donde realmente surge el valor; indica la raíz de todos los ciclos y formas del valor, apuntando hacia la explotación de la fuerza de trabajo.

Esta sucesión de las metamorfosis del capital en acción implica la comparación constante de los cambios de magnitud de valor del capital operados en el ciclo de su valor originario. La sustantivación del valor frente a la fuerza creadora de valor, o sea, la fuerza de trabajo, se inicia con el acto D-T (compra de la fuerza de trabajo) y se realiza, como explotación de la fuerza de trabajo, durante el proceso de producción. (Ibíd. p. 95)

De esta manera queda claro que no puede existir valor sin explotación; esta complementariedad, que en realidad es una relación que hace parte de un complejo de relaciones más amplio, es lo que caracteriza la lógica del capital, es decir, la dinámica inmanente o ley tendencial. El objetivo de la 
sociedad capitalista es la producción y reproducción ampliada de valor, para lo cual son indispensables ciertas categorías o relaciones sociales, que no pueden ser sobrestimadas, o por el contrario, subestimadas.

El análisis del capital debe ser una evaluación objetiva de las condiciones en las que se desarrollan las relaciones sociales; este fue el principal objetivo y el mayor logro de Karl Marx al constituir un método de investigación fundado en la perspectiva de historicidad y totalidad, a través del cual evidencia la lógica (leyes tendenciales como dinámica inmanente) del modo de producción, y los impactos que éste ejerce sobre las relaciones sociales.

La investigación de Marx frente a la sociedad capitalista es una síntesis de análisis filosóficos, culturales, políticos, históricos y económicos que muestran la relación indisoluble entre todos esos elementos; su propuesta de conocimiento científico, contrario a las "Ciencias Sociales", rompe con la fragmentación y los muros (epistemológicos) imaginarios que determinan objetos específicos de una u otra ciencia, que fragmentan la unidad lógica en la que se presenta la realidad histórico-concreta.

\section{Consideraciones finales}

La teoría social de Marx es una propuesta de análisis que se propone conocer las principales características de la sociedad capitalista (sus leyes tendenciales), y a su vez, aportar en la transformación social que supere el modo de producción/reproducción. Con este objetivo fue que Karl Marx, dando continuidad a desarrollos teóricos precedentes, logró descubrir los elementos centrales la ley del valor-trabajo.

Según lo anterior, el análisis de la sociedad capitalista no puede estar basado en planteamientos superficiales fragmentarios o morales del metabolismo del capital. Solo el descubrimiento de las leyes tendenciales posibilitará una crítica radical que muestra las relaciones sociales como realmente son. De acuerdo con Marx, no se transforma de manera consciente lo que no se conoce; ello implica que para superar el orden capitalista, se tiene como 
presupuesto el análisis de su dinámica inmanente. A partir del conocimiento de la realidad objetiva se tienen las condiciones necesarias para unificar teoría y praxis, articuladas en un proyecto social emancipartorio.

Sin embargo, la obra de Marx es poco conocida, fragmentada o distorsionada tanto en las organizaciones socio-políticas de las décadas 1960 y 1970, como en los centros de formación universitaria. El Marx que pretende indagar la totalidad del modo de producción capitalista es sustituido por una interpretación fragmentaria, que centra sus argumentos en interpretaciones politicistas.

El Movimiento de la Reconceptualización, marcado por el contexto latinoamericano de organizaciones e ideales revolucionarios, incorporó la obra de Marx en su parte política, la cual, llevado al extremo, creó una forma de politicismo estéril fundado en el voluntarismo mesiánico. El supuesto "Agente de Cambio" destinado a orientar las transformaciones estructurales desconocía la lógica del capital, y por tanto otorgaba poderes extraordinarios a la lucha política y los individuos que en ella se podrían inscribir desde el escenario profesional. El choque de realidad demostró los equívocos de planteamientos voluntaristas, el cual, sumado a los nuevos contextos neoliberales, propiciaron la reinstalación de perspectivas conservadoras y neoconservadoras caracterizadas por el fatalismo, o por la apología abierta a las relaciones propias del capital.

Al señalar la ausencia de la crítica de la economía política, o su tergiversación, son comprensible los equívocos de la Reconceptualización sobre el análisis de las condiciones objetivas del momento vivido. El análisis de la realidad que privilegia y limita la interpretación de elementos políticos, desconoce la centralidad de la teoría del valor-trabajo, lo que conlleva equívocos teóricos y prácticos.

E1 Trabajo Social, como profesión dio un gran salto cualitativo durante las décadas 1960-1970 al introducir el marxismo en su arsenal teórico-metodológico; sin embargo, el salto cualitativo no fue plenamente consolidado. Ahora bien, las condiciones objetivas que brinda la historia, abren la posibilidad de profundizar el salto cualitativo, no para hacer del Trabajo Social 
una profesión "marxista", sino para que Marx y el marxismo tengan una participación más cualificada y competente al interior de las tensiones que se tejen en la lucha por la orientación de un proyecto profesional ético-político.

Recebido em 18/1/18 - Aprovado em 18/6/18

\section{Referências bibliográficas}

IAMAMOTO, Marilda. Servicio Social y División del Trabajo. 2 ed. São Paulo: Cortez, 2001.

IAMAMOTO, Marilda; CARVALHO, Raul. Relaciones sociales y Trabajo Social. 3 ed. Lima: CELATS/ Editorial Alfa S.A., 1984.

MARX Karl. Grundrisse. Manuscritos econômicos de 1857-1858. Esboços da crítica da economia política. São Paulo/Rio de Janeiro: Boitempo/UFRJ Editora, 2011.

. Contribuição à crítica da economia política. São Paulo: Expressão Popular, 2008.

. El Capital. Crítica de la economía política. Tomo I. Bogotá: Fondo de Cultura Económica, 1976.

El Capital. Crítica de la economía política. Tomo II. Bogotá: Fondo de Cultura Económica, 1975.

. El Capital. Crítica de la economía política. Tomo III. México D.F.: Fondo de Cultura Económica, 1968.

. Teoria da mais-valia. História crítica do pensamento econômico. Livro IV de "O Capital”. São Paulo: Difel, 1985.

NETTO, José Paulo. Capitalismo monopolista e Serviço Social. 8. ed. São Paulo: Cortez, 2012.

. Método y teoría en las diferentes matrices del servicio social. In: BORGIANNI, Elisabete; MONTAÑO, Carlos. Metodología y Servicio Social. Hoy en debate. São Paulo: Cortez, 2000. 
QUIROGA, Consuelo. Invasión positivista en el marxismo: el caso de la enseñanza de la metodología en el Servicio Social. In: BORGIANNI, Elisabete; MONTAÑO, Carlos. Metodología y Servicio Social. Hoy en debate. São Paulo: Cortez, 2000.

ROSDOLSKY, Roman. Génesis y estructura de El Capital de Marx. Estudios sobre los Grundrisse. México D.F.: Siglo XXI Editores, 1989.

\section{Nota do autor}

Sergio Quintero Londoño - Bolsista Nota 10 FAPERJ. Magister en Servicio Social por la Universidad Federal de Rio de Janeiro (UFRJ). Trabajador Social egresado de la Universidad de Caldas - Colombia. E-mail: seranquilog@hotmail.com 